\title{
El comercio Electrónico y la Aduana
}

\section{Electronic Commerce and Customs}

\author{
*Servín Sánchez, S. \\ Universidad Columbia del Paraguay
}

\section{RESUMEN}

El objetivo primordial de esta investigación es examinar la aplicabilidad de impuestos a las operaciones comerciales y financieras realizadas a través de medios electrónicos de comunicación. Para el desarrollo de este estudio se revisaron la ley 2422/2004 y su reglamentación el decreto 4672/2005, demás leyes aplicables al de impuesto a la renta e impuesto al valor agregado en el contexto del comercio electrónico. Este trabajo de investigación metodológicamente se consideró descriptivo y documental, por cuanto se sustentó de la revisión a textos, doctrina, leyes, entre otras. Los resultados obtenidos demuestran el desarrollo del comercio electrónico como actividad económica y el avance legal que ha brindado seguridad en las operaciones. En cuanto a la aplicación del impuesto a la renta, resulta difícil por no poderse determinar el vínculo, o sea, el establecimiento permanente y respecto al Impuesto al Valor Agregado, presenta inconveniencia para gravar los bienes y servicios adquiridos on line e intangibles. También los tributos aduaneros son difíciles de ser aplicados en casos de intangibles y transacciones electrónicas por ser éstas susceptibles de omisión documentaria física y porque el establecimiento principal del contribuyente en la mayoría de los casos es difícil de ubicar. Se concluye que es necesario fortalecer el comercio electrónico, seguir legislando para dar seguridad a las operaciones que se realicen y se resalta la conveniencia de gravar correctamente las operaciones por este medio transaccional.

Palabras clave: Comercio Electrónico, Globalización, Internet, Impuesto al Valor Agregado, Impuesto a la Renta, Tributos Aduaneros.

\section{ABSTRACT}

The primary objective of this research is to examine the applicability of taxes on trade and financial transactions through electronic media. For the development of this study law 2422/2004 and your regulations of decree $4672 / 2005$, other applicable provisions of the income tax and value added tax in the context of electronic commerce laws were revised. This research was considered methodologically descriptive and documentary was sustained because of the review texts, doctrine, laws, among others. The results show the development of electronic commerce as an economic activity and the progress that has provided legal security operations. As to the application of income tax, it is difficult not to be able to determine the link, ie the permanent establishment and with respect to Value Added Tax, presents inconvenience to tax goods and services purchased on line and intangible. Customs duties are

*Autor Correspondiente: Lic. Sergio Milton Servín Sánchez. Licenciatura en Administración de Empresas. Universidad Columbia del Paraguay

Email: smss2660@gmail.com

Fecha de recepción: setiembre 2015; Fecha de aceptación: noviembre 2015 
also difficult to be applied in cases of intangibles and e-business because these are susceptible to physical and documentary omission because the taxpayer's principal place of business in most cases it is difficult to locate. We conclude that it is necessary to strengthen e-commerce continue to legislate to give security to the operations carried out correctly and the desirability of taxing transactional operations by this means is highlighted.

Keywords: Electronic Commerce, globalization, Internet, Value Added Tax, Income Tax, Customs Taxes.

\section{INTRODUCCIÓN}

Este trabajo de investigación tiene como objetivo examinar la aplicabilidad de impuestos a las operaciones mercantiles realizadas a través de medios electrónicos de comunicación (redes, internet etc.). Las preguntas de investigación son: ¿Qué aplicación tienen los impuestos IRACIS e IVA a las transacciones mercantiles? ¿Cuáles serían las bases imponibles de los impuestos a ser aplicados a las transacciones realizadas por medios electrónicos?. Esta investigación pretende dar una visión global a la revisión de la literatura existente sobre el tema y realizar un análisis descriptivo sobre las diversas teorías y modelos tributarios que podrían ser aplicados y sus características en relación al comercio electrónico.

La creciente internacionalización de la economía paraguaya, en la cual se ha producido un incremento sostenido del volumen de las exportaciones y de las importaciones en los últimos 10 años, exigen que la Aduana cumplan con su rol de facilitador del comercio internacional, lo cual es un gran reto dada la poca flexibilidad para la contratación de nuevo personal y la existencia de normas de austeridad en el estado que restringen los gastos e inversiones, a pesar de contar con un alto presupuesto. La modernización de la Aduana Paraguaya llevada a cabo desde los años 90 del siglo pasado, se basó en la simplificación de los procedimientos aduaneros y el uso intensivo de las tecnologías de información, buscando principalmente mejorar la recaudación aduanera y hacer más eficientes los controles aduaneros, a vez de lograr la facilitación del comercio internacional dado que la política comercial Paraguaya cambio hacia la apertura del comercio internacional bajo los principios establecidos por la Organización Mundial de Comercio - OMC y dada la dinámica del Comercio Internacional en un entorno mundial marcado por la competitividad y la globalización.

Según (Fernández, 2010), este entorno de los años 90 exigió a las administraciones aduaneras, mayores esfuerzos en la facilitación del comercio internacional, pero a la vez plantea mayores retos en cuanto a los controles que debe efectuar en el tráfico internacional de mercancías, debiendo establecer procesos que simplifiquen los tramites y operaciones aduaneras sin descuidar el control, para lo cual soportan estos procesos en las tecnologías de información.

Es así que La aduana peruana, desde el inicio de su proceso de modernización en los años 90 ha hecho uso intensivo de las tecnologías de información para el trámite de los regímenes aduaneros, tanto para el registro transaccional de las operaciones, para consultas tanto internas como externas, así como para los procesos de control y fiscalización, implementando cada vez mayores servicios tanto para los usuarios internos como para los usuarios externos o clientes, en este caso los operadores de comercio exterior (Vergara Moncada, 2009, pág. 4). 
La Dirección Nacional de Aduanas desarrolló un sistema informático propio que contempla la gestión de los regímenes y operaciones aduaneras, la trazabilidad de la carga desde su arribo al país hasta su destinación aduanera y el control de la mercancía y de los procesos vinculados a los regímenes aduaneros. Este desarrollo a la vez ha requerido la identificación, documentación y simplificación de estos procesos de negocio evitando tareas repetitivas y que no generan valor agregado, disminuyendo así los costos asociados y recogiendo las necesidades de los operadores de comercio exterior permitiendo la facilitación del mismo (Vergara Moncada, 2009, pág. 5).

En un proceso posterior, se toma la decisión estratégica adoptar un sistema de gestión de la calidad en el marco de la norma ISO 9001/2000 cuyo convenio se estableció con la SGS Internacional y su posterior certificación, el cual es apoyado por la existencia de este sistema integrado de gestión de información basado en los procesos dela recaudación aduanera y desarrollado mediante una metodología orientada a los procesos, pues la filosofía de la norma ISO $9001 / 2000$ promueve la adopción de un enfoque basado en los procesos (Vergara Moncada, 2009).

Dado que la norma ISO 9001/2000se orienta a la satisfacción de las necesidades del cliente y a la gestión de los procesos, facilita la toma de decisiones sobre la base de información objetiva sobre el desempeño de los procesos y su impacto en las características de calidad. En este sentido el SGA cuenta con herramientas e indicadores que permiten monitorear la variabilidad de los procesos certificados, permitiendo así estandarizar la calidad del servicio, lo cual ha permitido lograr la mejora continua en los procesos certificados reduciendo significativamente el tiempo de despacho aduanero (Vergara Moncada, 2009, pág. 6).

Con el surgimiento del gobierno electrónico, entendido como la aplicación de las tecnologías de la información y comunicaciones en las entidades del estado que permiten transformar las relaciones entre el estado y los ciudadanos, empresas y demás organizaciones civiles, mediante el despliegue de servicios electrónicos a través de internet, surge una nueva etapa en la prestación de servicios por parte de la Aduana Paraguay para los ciudadanos y los operadores de comercio exterior, en la cual se han aprovechado las características del internet y el desarrollo del mismo en la Sociedad Paraguaya por el fenómeno de las del internet, para brindar servicios electrónicos de 24 horas durante los 7 días de la semana, lo cual ha mejorado la atención de las operaciones aduaneras.

Asimismo, la estrategia de gobierno electrónico del Poder Ejecutivo apoya los objetivos del sistema de gestión de calidad en cuanto a la orientación a las necesidades de los clientes, pues mediante el enfoque de integración de procesos y el uso de las tecnologías de información permite el acceso en línea de manera segura a los servicios que ofrece la Dirección Nacional de Aduanas a los operadores de comercio exterior.

En particular desde el punto de vista personal, como funcionario de aduanas con una experiencia de 34 años me motiva el poder brindar un aporte a la Dirección Nacional de Aduanas a fin plasmar un punto de vista crítico de los procesos de modernización y de adopción del gobierno electrónico que sirva para poder seguir mejorando los servicios ofrecidos a los ciudadanos y usuarios del comercio exterior. 


\section{METODOLOGÍA}

El enfoque de la investigación es cualitativo, porque se analizan las características de las legislaciones tributarias pertinentes y su relacionamiento con la Dirección Nacional de Aduanas y el Comercio Electrónico, en el impacto impositivo.

El Tipo de Estudio utilizado en este trabajo de investigación es descriptivo, porque se describen en la literatura las diversas teorías que relacionan el Comercio Electrónico y las características del funcionamiento de la Dirección Nacional de Aduanas.

La Técnica Empleada para la recolección de datos es documental/bibliográfica, pues se extrajeron las informaciones de libros, leyes y artículos científicos, el procesamiento de datos se hizo en el programa Word 2013, se utilizó el análisis crítico, reflexivo e interpretativo de los textos, para sustentar las opiniones emitidas las conclusiones y resultados.

\section{DESARROLLO \\ Principios fundamentales}

La Dirección Nacional de Aduanas es una persona de derecho público, encargada de la aplicación de la legislación y la recaudación de los tributos aduaneros de importación y exportación. Su función principal es la fiscalizar el tráfico de mercaderías por las fronteras y aeropuertos del país y la recaudación de los tributos en su consecuencia. En cuanto a sus atribuciones prioritarias ellas se dan en la zona primaria ya que en la zona secundaria su labor se reduce, casi exclusivamente a reprimir el contrabando.

Para adentrarnos al Comercio Electrónico en la Aduana Paraguaya es importante circunscribirnos en la implementación del Sistema informático Sofía, que tuvo sus orígenes hacia el año 1993 y que actualmente es soporte informático y tecnológico que cumple con los requisitos de tecnología de la información, automatización y comunicaciones en tiempo real entre todas las Personas Vinculadas al Comercio Internacional, y es una herramienta eficaz para procesar las declaraciones aduaneras, controlar la gestión, eliminar la burocracia en los trámites, poco relacionamiento entre los Despachantes y Auxiliares con los Funcionarios, mejora en el control, la gestión y la liquidación y cobro de los tributos (OMA, 2005, pág. 10).

El procesamiento electrónico que es la utilización de las claves de acceso, que son confidenciales, dan mayor seguridad al acto, que las Personas Vinculadas al Comercio Internacional en este caso los Despachantes de Aduana, los Importadores, Exportadores y todo Agente que interactúa en el proceso de desaduanamiento de una mercancía (OMA, 2005, pág. 12).

El uso de Tarjetas Inteligentes nace con el nuevo Código Aduanero la Ley $2422 / 2004$ que en su Art. $8^{\circ}$ del Reglamento de la Ley que es el Decreto $4672 / 2005$ está estipulado que se halla en vigencia plena. La gestión de los documentos de importación y exportación por el Sistema Informático llevan la firma manuscrita tanto de las personas vinculadas al comercio internacional como de los funcionarios aduaneros que participan en los trámites. Cuando dice que las firmas autógrafas que la Dirección Nacional de Aduanas requiera podrán ser sustituidas por contraseñas o signos adecuados, como la firma electrónica para la sustanciación de las actuaciones administrativas que se realicen por medios informáticos. En la Ley N²051/2003 de Contrataciones Públicas ya se previó este sistema de identificación al expresar que: la utilización de sistemas autorizados de identificación electrónica reemplazará a todos los efectos de firma autógrafa (Art. 81). 


\section{Marco Conceptual Establecido en la Ley 4017/2010}

A continuación se comentan algunos fragmentos de la ley 4017/2010 De Validez Jurídica de la Firma Electrónica, la Firma Digital, los Mensajes de Datos y El Expediente Electrónico

Firma electrónica: es el conjunto de datos electrónicos integrados, ligados o asociados de manera lógica a otros datos electrónicos, utilizado por el signatario como su medio de identificación, que carezca de alguno de los requisitos legales para ser considerada firma digital.(Congreso de la Nación Paraguaya, 2010).

Los datos y su compaginación serán establecidos mediante la legislación a ser desarrollada. Pues estos datos necesitan de suma confidencialidad, además de contienen información de orden lógico, cuyo mal uso podría dañar las transacciones comerciales.

Firma digital: es una firma electrónica certificada por un prestador acreditado, que ha sido creada usando medios que el titular mantiene bajo su exclusivo control, de manera que se vincule únicamente al mismo y a los datos a los que se refiere, permitiendo la detección posterior de cualquier modificación, verificando la identidad del titular e impidiendo que desconozca la integridad del documento y su autoría (Congreso de la Nación Paraguaya, 2010).

Las empresas que se dediquen a la creación y certificación de firmas digitales tendrán las infraestructuras necesarias para la realización del proceso de digitalización de la información. Además se encargarán de la validación del titular de la información, mediante procesos rigurosos de control tecnológico.

Mensaje de datos: es toda información generada, enviada, recibida, archivada o comunicada por medios electrónicos, ópticos o similares, como pudieran ser, entre otros, el intercambio electrónico de datos (EDI), el correo electrónico, el telegrama, el télex o el telefax, siendo esta enumeración meramente enunciativa y no limitativa.(Congreso de la Nación Paraguaya, 2010)

Documento Digital: es un mensaje de datos que representa actos o hechos, con independencia del soporte utilizado para su creación, fijación, almacenamiento, comunicación o archivo (Congreso de la Nación Paraguaya, 2010).

Los documentos digitales podrán tener diversos formatos de archivos, tales como: PDF, JPEG, Word, Excel etc. dichos documentos tendrán la opción de ser firmados digitalmente en su estructura interna, y podrán ser contrastados y comprobados mediante programas identificadores de la firma digital.

Firmante, suscriptor o signatario: es toda persona física o jurídica titular de la firma electrónica o digital. Cuando el titular sea una persona jurídica, ésta es responsable de determinar las personas físicas a quienes se autorizarán a administrar los datos de creación de la firma electrónica o digital (Congreso de la Nación Paraguaya, 2010).

Los niveles de autorización en el caso de personas jurídicas deberá ser reglamentado para evitar confusiones en cuanto a la responsabilidad que conlleva esa firma frente a los actos jurídicos y administrativos.

Expediente electrónico: se entiende por "expediente electrónico", la serie ordenada de documentos públicos registrados por vía informática, tendientes a la formación de la voluntad administrativa en un asunto determinado (Congreso de la Nación Paraguaya, 2010).

La ventaja de los expedientes electrónicos es que conllevarán el menor uso del papel físico en las oficinas, y por ende el ahorro en espacio y costos de 
almacenamiento. Además de que podrán ser los expedientes electrónicos, fácilmente transportables.

\section{CONCLUSIONES}

En el campo de los impuestos especiales, además de los problemas generales que el comercio electrónico conlleva en los gravámenes que recaen sobre el tráfico de bienes o de las dificultades crecientes que éste puede producir para controlar unas transacciones informáticas en el régimen suspensivo de circulación intracomunitaria, pueden aparecer cuestiones nuevas como son la compra masiva por el consumidor final de productos gravados por estos Impuestos por medio de la Red y sin control fiscal, especialmente, si se desarrollan las transacciones por medio de pequeños paquetes, con franquicia aduanera y exenciones en el IVA.

Un primer problema que se plantea a las Aduanas es la dificultad para controlar en la frontera transmisiones que no conllevan entregas físicas, sino que se realizan de forma electrónica, entre medios informáticos.

En segundo lugar, muchas transacciones internacionales desplazan su valor a prestaciones de servicios, donde documentos de fácil traslado (planos, disquetes de ordenador, CD-ROMS,...) atraviesan sin control posible la frontera 0 , incluso, se trasmiten sin necesidad de transporte físico, por lo que la tradicional Aduana, centrada en la vista y control de la mercancía y su envase o embalaje, tiene grandes dificultades para controlar la operación y hacerla tributar.

Asimismo, las reglas de valor aduanero se enfrentan a nuevos desafíos, ya que la mayor parte de la base imponible no va en el bien físico, sino en el servicio incorporado.

Por último, las facilidades que ahora están pensadas para facilitar el tráfico sin relevancia económica, por ejemplo, la exención para los pequeños paquetes, pueden generar nuevas vías de elusión fiscal u obligar a la reforma de la regulación en esta materia.

En base a los análisis realizados se sugiere que son de suma importancia creciente los activos intangibles como recursos generadores de valor para las empresas en el siglo XXI, a tal punto que han producido un importante cambio al posibilitarles mejorar la oferta de bienes y servicios, llegar a mercados, otrora, inalcanzables, producir nuevos tipos de relaciones con socios, clientes y proveedores, movilizar las habilidades y la motivación continua de los empleados $y$, en fin, aplicar las más modernas tecnologías, bases de datos, sistemas de información y listado de clientes en forma eficiente ${ }^{1}$.

Además se recomienda para las empresas, la identificación, gestión y medición de sus intangibles resulta de fundamental importancia para el éxito de los negocios, dado que con ello se fortalece la posición financiera de la compañía y se maximiza la riqueza de los accionistas, de la misma manera en contrapartida, los intangibles son más difíciles de identificar, medir y que aquellos activos tangibles.

Es por ello que muchos de los recursos financieros aplicados en los intangibles no se encuentran registrados en los estados financieros de las empresas, dada la incapacidad de las normas internacionales de información

\footnotetext{
${ }^{1}$ La eficiencia está definida por la RAE (2013) como: Capacidad de disponer de alguien o de algo para conseguir un efecto determinado.
} 
financiera ${ }^{2}$ para capturar información y prescribir como registrarlo de forma adecuada.

Esta falta de información completa y homogénea en los estados financieros de la empresa impide que la misma conozca, en forma total y acabada, sus potencialidades lo cual afecta la toma de decisiones.

De igual manera, como esta información financiera y contable parcializada de los intangibles afectan negativamente la información económica y financiera para la toma de decisiones y para el conocimiento adecuado de los agentes económicos, también, repercute negativamente en la incidencia tributaria de los diferentes sistemas tributarios, sea en la tributación directa como en la tributación indirecta ${ }^{3}$.

Por otro lado, además de la registración contable incompleta y a veces deficiente se debe tener en cuenta también una asimetría ${ }^{4}$ en el tratamiento que reciben en los diferentes países permitiendo en algunos que se contabilice como activos en otros como gastos o costos y en otros directamente no se registran, y ello a su vez determina un tratamiento tributario confuso y a veces inadecuado.

La ley tributaria paraguaya (ley $125 / 91$ modificada por la ley $2421 / 2004)^{5}$ no contiene disposiciones que establezcan criterios definidos para el tratamiento tributario de los activos intangibles, especialmente con aquellos que en cuanto a su valor es dificultoso de determinar, como sería el caso de los conocimientos técnicos y de mercado que ha adquirido el personal de la empresa, o la cartera de clientes.

La reglamentación ${ }^{6}$ establece que en caso que son activables no compadeciéndose de las normas de contabilidad que son más estrictas para sus reconocimientos como activos, y ello, puede llegar a producir discordantes entre el informe de auditoría ${ }^{7}$ y el criterio impositivo.

No existe ninguna disposición que expresamente derive la cuestión de los intangibles a los principios de contabilidad, razón por la cual, se asume tácitamente que estos principios son los que rigen cuando la norma tributaria no dispone otra solución.

Pero al no derivar la ley a la norma de contabilidad, este criterio queda en entredicho y sujeto a interpretación. Por ello es recomendable que en las cuestiones técnicas de las normas contables, cuando ello no afecte la eficiencia del impuesto, y, antes bien, se derive su solución a las normas contables.

No existe un cuadro de amortización de los activos intangibles que los clasifique y que considere los años de protección para establecer su periodo de amortización. Las normas antielusivas ${ }^{8}$ que contiene nuestro sistema tributario son muy generales careciendo de la especificidad que la realidad del mundo de los negocios actualmente exige.

\footnotetext{
${ }^{2}$ Las Normas Internacionales de Información Financiera NIIF's son establecidas por la International Accounting Standards Board (IASB) y sirven de delineamientos para las registraciones contables.

${ }^{3}$ En la tributación directa entran los Impuestos a los Ingresos y en la tributación indirecta, los impuestos al consumo.

${ }^{4}$ La asimetría está establecida principalmente por las peculiaridades de las normas tributarias de los países y no por las normas contables.

${ }^{5}$ Además se incluyen los numerosos decretos reglamentarios del Poder Ejecutivo y las resoluciones administrativas emitidas por la Sub Secretaria de Estado de Tributación (SSET).

${ }^{6}$ Establecida por la Administración Tributaria (Sub Secretaria de Estado de Tributación SET).

${ }^{7}$ El informe de auditoría según las Normas Internacionales de Auditoria (NIA's) establecidas por la IFAC.

${ }^{8}$ Son aquellas normas que tratan de evitar la evasión impositiva.
} 
Tampoco existe un marco legal adecuado para el tratamiento de los precios de referencia ${ }^{9}$, no solo de los bienes tangibles, sino también y especialmente en el caso de los intangibles, que además de su inmaterialidad que permite su uso o adquisición vía internet mediante el llamado comercio electrónico, su precio puede ser vilmente manejado para obtener ventajas fiscales de los diferentes sistemas tributarios.

En el Paraguay no existe un régimen específico de incentivos para el desarrollo y producción tecnológica, aunque si existen regímenes de beneficios fiscales $^{10}$ para la inversión en actividades convenientes o necesarias para nuestro país.

Los registros contables y las documentaciones respaldatorias que constituyen la base de la información de los ingresos, gastos e inversiones, a los efectos de determinar la existencia de hechos imponibles gravados por los sistemas tributarios nacionales, presentan serios problemas al momento del reconocimiento inicial de los activos intangibles, lo cual afecta la correcta aplicación de los impuestos vigentes.

A consecuencia de estas deficiencias, existen intangibles que se activan, como por ejemplo una patente de un tercero o una marca, existen intangibles que se consideran gastos, como los costos de investigación y desarrollo o asistencia técnica, y existen igualmente que no se contabilizan como el valor del capital humano de la empresa.

Las legislaciones impositivas no deberían interponerse en el campo de las ciencias contables, especialmente en aquellos casos de intangibles de generación propia ${ }^{11}$, dejando a las mismas la determinación del tratamiento contable aplicable en cada caso, y determinar en forma expresa, que norma de contabilidad la ley debería seguir.

Una depreciación acelerada ${ }^{12}$ de los activos intangibles puede significar su desaparición contable cuando aún genera flujos de efectivos y rentas, lo cual afecta al patrimonio del contribuyente y también a los impuestos pagados, dada su afectación al cuadro de resultados.

Con este trabajo de investigación se demostró la importancia de tener legislaciones concretas sobre los intangibles en Paraguay, especialmente en lo tributario para poder determinar que es un activo intangible, los criterios para su reconocimiento, su forma de valuación y los impuestos afectados en forma clara sobre los mismos.

Por lo tanto, se propone adecuar el marco normativo de la Ley $125 / 91$ modificada por la ley 2421/2004 y la Ley 5061/2013 a la tributación de intangibles, estableciéndose una tasa diferenciada del IVA de acuerdo a los convenios que tenga el Paraguay con los países del Mercosur, y otra tasa para países de extrazona. Además se debe adecuar el modelo de facturación de acuerdo a las facturas tipo exportación y los comprobantes de retención tienen que tener también un formato internacional. La firma digital será el medio de validar las facturaciones, pues ya se tienen los soportes legales establecidos en

\footnotetext{
9 Los precios de referencia, en lo concerniente a transacciones internacionales se dan a llamar precios de transferencia internacionales, los cuales no están reglamentados en Paraguay, esto afecta significativamente al IRACIS.

${ }^{10}$ Algunos beneficios fiscales están establecidos en la Ley 1064/1997 de Maquila.

${ }^{11}$ Son aquellos realizados por la producción científica del conocimiento, como ejemplo se tienen a las patentes.

${ }^{12}$ Las depreciaciones aceleradas no son deducibles a efectos del IRACIS, según lo establecido en el decreto 6359/05.
} 
nuestra legislación para su adecuación a las transacciones comerciales vía internet.

\section{REFERENCIAS BIBLIOGRÁFICAS}

Congreso de la Nación Paraguaya. (2004). Ley N² 2422/2004 Código Aduanero. Asunción: Congreso de la Nación Paraguaya.

Congreso de la Nación Paraguaya. (2010). Ley No 4017/2010 De Validez de la Firma Electrónica, la Firma Digital, los Mensajes de Texto y el Expediente Electrónico. Asunción: Congreso de la Nación Paraguaya.

Consejo del Mercado Común. (2006). Convenio de Cooperación, Intercambio de Información, Consulta de Datos y Asistencia Mutua entre las Administraciones Aduaneras del Mercosur. Brasilia: Consejo del Mercado Común.

Fernández, F. (2010). Comercio Electrónico Implicancias Impositivas y Aduaneras. Buenos Aires: FACPCE.

OMA. (2005). Marco Normativo para asegurar y facilitar el Comercio Mundial. Bruselas: Organización Mundial de Aduanas.

Reyes, E. (2014). La Tendencia de la Aduana: El Despacho Aduanero Electrónico. México D.F.: Aduana México.

Vaquer, I. (2013). Teletrabajo en Comercio Exterior. Buenos Aires: UCES.

Vergara Moncada, R. (2009). Uso de las TIC en Website la Sunat y Aduanas. Quipukamayoc, 157-168.

Zamudio, O. (2014). La Logística y el Comercio Electrónico como Factor de Competitividad para las Pequeñas y Medianas Empresas Mexicanas en el Comercio Mundial (Proyecto de Tesina). Barcelona: Universidad de Barcelona. 